\title{
Anti-tubulin Monoclonal Antibodies That Bind to Specific Neurons in Caenorhabditis elegans
}

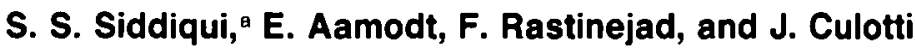 \\ Department of Biochemistry, Molecular and Cell Biology, Northwestern University, Evanston, Illinois 60201
}

\begin{abstract}
We have identified 2 anti-tubulin monoclonal antibodies that bind to 2 different subpopulations of identified neurons in the simple nervous system of the nematode Caenorhabditis elegans. The antibodies also recognize specific tubulin isotypes from $C$. elegans that were separated by isoelectric focusing. Antibody 6-11B- 1 intensely stained the mechanosensory neurons ALML, ALMR, PLML, PLMR, PVM, and AVM, plus neuron PVR by indirect immunofluorescence, and it bound to 1 of 2 major $\alpha$-tubulin isotypes separated by isoelectric focusing. The epitope for antibody (Ab) 6-11B-1 is acetylated $\alpha$-tubulin (Piperno and Fuller, 1985). Antibody 2-2833 stained a set of neurons that contain the neurotransmitter GABA. It bound to the 2 major and 1 of the minor $\beta$-tubulin isotypes of $C$. elegans. These results suggest that specific $\alpha$ - and $\beta$-tubulin isotypes are greatly enriched in the subsets of neurons recognized by these antibodies. Most (possibly all) of the neurons in each subset are functionally related. The antibodies should allow us to examine whether specific tubulin isotypes have specific functions in these neurons. They may also be useful for examining neuron morphologies in mutants of $C$. elegans which affect nerve development.
\end{abstract}

Microtubules are required for many well-characterized functions in eukaryotic cells. including the movement of chromosomes in mitosis and meiosis. intracellular transport, establishment and maintenance of cellular morphology, ccll growth, cell migration, and morphogenesis in multicellular organisms. Most eukaryotes contain a diversity of tubulin isotypes (Field and Lec, 1985) which represent both different tubulin gene products and posttranslational modifications of tubulins (reviewed by Cleveland and Sullivan, 1985).

Since the functional diversity of microtubules is paralleled by molecular diversity as evidenced by tubulin isotypes, and since certain isotype-specific amino acid sequences are evolutionarily conserved (Cleveland and Sullivan, 1985), it is tempting to speculate that specific tubulin species have specific functional roles.

\footnotetext{
Received Sept. 2, 1988; rcvised Feb. 1, 1989: accepted Feb. 9, 1989

We would like to thank I.inda Gremke, Rohert Holmgren. Stephanie Jones, and Gianni Piperno for ideas and discussions: Gianni Piperno and T. Arai for antibodies; William Klcin and Frank Ncuhaus for sharing equipment; and Greg Skorupa for technical assistance. This research was supported by NIH grant NSO7738 to E.A. and by a Basil U' Connor grant from the March of Dimes Foundation and NIH grant NS20258 to J.C.

Correspondence should be addressed to Joseph G. Culotti at his present address: Department of Molecular Immunology and Neurobiology, Mt. Sinai Hospital Research Institute. Toronto M5G 1 X5, Canada.

- Present address: Laboratory of Molecular Biology. Toyohashi University of Technology, Tempaku-cho. Toyohashi. 440 Japan.

Copyright ci 1989 Socicty for Neuroscience 0270-6474/89/082963-10\$02.00/0
}

However, ascription of specific tubulin isotypes to specific functions has been difficult. For example, it has been shown by the use of isotype-specific antibodies that both interphase cytoskeletal and mitotic spindle microtubules are mixed copolymers of expressed $\beta$-tubulin isotypes in mammalian cells (Lewis et al., 1987). In these experiments, even a hematopoietic tissuespecific $\beta$-tubulin isotype was assembled into all microtubules (including marginal band, interphase, and mitotic microtubules) in hematopoietic cells and when transfected into HeLa cells growing in culture. These results suggest that different $\beta$-tubulins can substitute for onc another in certain, but perhaps not all, cellular functions.

The studies to date have been limited to a small number of mammalian cell types that express only one kind of microtubule structure at any given time. Other cells from multicellular organisms, such as neurons, in which more than one microtubule type may be present simultaneously, have not yet been examined in detail, nor have many cells been examined in the context of the the whole organism.

The use of specific antibodies to deduce the functions of specific tubulins in multicellular organisms would be particularly enlightening if applied to an anatomically simple organism in which the cellular distribution of different tubulins could be cstablished with precision. An excellent organism for this approach is the frec-living soil nematode Caenorhabditis elegans. This organism reproduces as a self-fertilizing hermaphrodite. The adult hermaphrodite has 959 cells, 302 of which are neurons (White et al., 1986). The developmental lineages that produce thesc cells have been completely described (Sulston and Horvitz, 1977; Sulston et al., 1983), and the structure of the entire adult nervous system is known (White et al., 1986). Many cells in this organism, especially neurons, can be uniquely identified by their relative position and/or morphology. The remaining cells can be identified by following the lineages that generate them, as the lineages are essentially invariant among wild-type individuals (Sulston and Horvitz, 1977; Sulston et al., 1983). C. elegans has the added advantage that it is amenable to genetic analysis. Hundreds of behavioral and morphological mutants of C. elegans, including ones affecting microtubules, have becn isolated and genetically characterized (Brenner, 1974; Lewis and Hodgkin, 1977; Chalfie and Sulston, 1981; Perkins et al., 1986).

In addition, $C$. elegans possesses structurally diverse microtubule types that probably have different functions. Within the nervous system, for cxample, there are 3 kinds of ultrastructurally distinct microtubules. Eleven-protofilament microtubules are found in all ncurons and other tissues and represent the most abundant microtubules in the organism (Chalfie and Thomson, 1982). Bundles of 15 -protofilament microtubules are found in a small number of mechanosensory neurons that me- 
diate touch sensitivity in C. elegans (Chalfie and Sulston, 1981). These large-diameter microtubules are probably required for sensory transduction since touch-insensitive mutants have been found in which cellular morphology is normal, but the 15-protofilament microtubules are absent (Chalfie and Sulston, 1981). Finally, 13-protofilament microtubules are found in the A subfibers of doublet microtubules present in the sensory cilia of $C$. elegans (Chalfie and Thomson, 1982). The ultrastructural analysis of various sensory mutants of $C$. elegans suggests that these microtubule structures are also required for sensory transduction in the cells possessing them (Lewis and Hodgkin, 1977; Albert et al., 1981; Perkins et al., 1986).

Here we report the identification of 2 monoclonal antibodies that exhibited preferential immunocytochemical staining of 2 distinct subsets of neurons in the simple nervous system of $C$. elegans and also bound to specific tubulin isotypes from this organism. Since most of the neurons within each stained subset are known to be functionally related, these antibodies may be useful in deducing the roles that different tubulin isotypes play in nerve development, function, or maintenance in $C$. elegans as well as perhaps in other organisms.

\section{Materials and Methods}

Materials. The monoclonal antibodies 2-28-33 and 6-11B-1 used in this study were kindly provided by Dr. Gianni Piperno, Rockefeller University. Monoclonal antibody E6B6 was kindly provided by Dr. Takao Arai.

Taxol was generously provided by the Natural Products Branch, Division of Cancer Treatment, National Cancer Institute. Other sources of materials were Bio-Rad Laboratories (Richmond, CA): acrylamide, bis-acrylamide, Coomassie blue R-250, and ammonium persulfate; Pharmacia Inc. (Piscataway, NJ): DEAE-Sephadex A-50; Aldrich Chemical Co. Inc. (Milwaukee, WI): ultrapure tris[hydroxymethyl]aminomethane; Schwarz/Mann Biotech (Cleveland, $\mathrm{OH}$ ): ultrapure urea; LKB Instruments Inc. (Bromma, Sweden): ampholines; Cooper Biomedical (Malvern, PA): rhodamine-conjugated goat anti-mouse IgG; and Sigma Chemical Company (St. Louis, MO): paraformaldehyde, gelatin, Hoechst 33258 , and $n$-propylgallate. The sources of the other materials were described previously (Aamodt and Culotti, 1986).

PEM buffer has been described (Aamodt and Culotti, 1986). H-buffer contained $20 \mathrm{~mm}$ sodium phosphate, $1.0 \mathrm{~mm} \mathrm{MgSO}_{4}, 1.0 \mathrm{~mm}$ EGTA, $2.0 \mathrm{~mm}$ DTE, $40 \mu \mathrm{g} / \mathrm{ml}$ leupeptin, $40 \mu \mathrm{g} / \mathrm{ml}$ pepstatin, $1.0 \mathrm{mg} / \mathrm{ml}$ TAME (N- $\alpha-p$-tosyl-L-arginine methyl ester) at $\mathrm{pH}$ 6.8. C-buffer contained $20 \mathrm{~mm}$ sodium phosphate, $1.0 \mathrm{mM} \mathrm{MgSO}_{4}, 1.0 \mathrm{~mm}$ EGTA, 0.1 mM GTP, $2.0 \mathrm{~mm}$ DTE, $2.0 \mu \mathrm{g} / \mathrm{ml}$ leupeptin, $2.0 \mu \mathrm{g} / \mathrm{ml}$ pepstatin, $0.1 \mathrm{mg} / \mathrm{ml}$ TAME at $\mathrm{pH} 6.8$. PBS contained $0.1 \mathrm{~m}$ sodium phosphate, $0.15 \mathrm{M} \mathrm{NaCl}$ at $\mathrm{pH} 7.4$.

Maintenance and growth of nematode strains. Wild-type Caenorhabditis elegans var. Bristol (strain N2) was cultured as described by Brenner (1974). Large quantities of C. elegans were grown and harvested as described previously (Aamodt and Culotti, 1986).

Isolation of tubulin from $\mathrm{C}$. elegans. $C$. elegans were thawed, mixed with 2 parts of ice-cold H-buffer, and homogenized in a French press at 12,000 psi. The homogenate was centrifuged at $40,000 \times g$ for 30 min at $0^{\circ} \mathrm{C}$. The pellet was discarded and the supernatant was centrifuged at $140,000 \times g$ for $60 \mathrm{~min}$ at $0^{\circ} \mathrm{C}$. The second pellet was also discarded, and ammonium sulfate was added to the supernatant to $50 \%$ saturation. The mixture was centrifuged at $27,000 \times g$ for $20 \mathrm{~min}$ at $0^{\circ} \mathrm{C}$. The supernatant was discarded, and the pellet was resuspended in $30 \mathrm{ml}$ of $\mathrm{C}$-buffer and centrifuged at $12,000 \times g$ for $10 \mathrm{~min}$ at $0^{\circ} \mathrm{C}$. The supernatant was applied to a $30 \mathrm{ml}$ DEAE-Sephadex column preequilibrated with C-buffer. The column was washed with $200 \mathrm{ml}$ of C-buffer containing $0.35 \mathrm{M} \mathrm{NaCl}$, and then the tubulin was eluted with C-buffer containing $0.65 \mathrm{M} \mathrm{NaCl}$. Ammonium sulfate was added to $50 \%$ saturation to the tubulin-containing fractions, and the mixture was centrifuged at $27,000 \times g$ for $20 \mathrm{~min}$ at $0^{\circ} \mathrm{C}$. The pellet was resuspended and frozen in PEM buffer containing $2.0 \mathrm{~mm}$ DTE, $0.1 \mathrm{mM}$ GTP, and 1.0 $\mathrm{M}$ glycerol. The next morning the mixture was thawed and centrifuged at $40,000 \times g$ for $30 \mathrm{~min}$ at $0^{\circ} \mathrm{C}$. Then $1.0 \mathrm{mM}$ GTP and $20 \mu \mathrm{M}$ taxol were added to the supernatant. The solution was warmed to $37^{\circ} \mathrm{C}$ for $5 \mathrm{~min}$ and then layered over a mixture of PEM buffer containing $10 \%$ sucrose, $1.0 \mathrm{M}$ glycerol, $1.0 \mu \mathrm{M} \mathrm{GTP}$, and $20 \mu \mathrm{M}$ taxol in a centrifuge tube. The mixture was centrifuged at $140,000 \times \mathrm{g}$ for $30 \mathrm{~min}$ at $30^{\circ} \mathrm{C}$. The pellet was resuspended in approximately $2.0 \mathrm{ml}$ PEM buffer containing $1.0 \mathrm{~mm}$ GTP, $20 \mu \mathrm{M}$ taxol, and $0.4 \mathrm{M} \mathrm{NaCl}$, warmed to $37^{\circ} \mathrm{C}$ for $5 \mathrm{~min}$, and then centrifuged at $27,000 \times \mathrm{g}$ for $30 \mathrm{~min}$ at $30^{\circ} \mathrm{C}$. The pellet was resuspended in PEM buffer for a final tubulin concentration of $3-4 \mathrm{mg} / \mathrm{ml}$.

Tubulin was isolated from bovine brain by the method of Shelanski et al. (1973), with 3 cycles of assembly and disassembly. The tubulin was separated from the microtubule associated proteins (MAPs) by phosphocellulose chromatography (Weingarten et al., 1975; Detrich and Williams, 1978), as described in Aamodt and Williams (1984).

Electrophoresis. SDS-gel electrophoresis was done in 10\% polyacrylamide gels (Laemmli, 1970). Molecular-weight standards were myosin, $\beta$-galactosidase, phosphorylase B, BSA, and ovalbumin (Bio-Rad Laboratories, Richmond, CA).

Isoelectric focusing was done as described by Field et al. (1984) on an LKB Multiphore apparatus. The gels $(160 \times 180 \times 0.75 \mathrm{~mm})$ were prefocused at $8 \mathrm{~W}$ for $30 \mathrm{~min}$ at $5^{\circ} \mathrm{C}$. The protein samples $(10-120 \mu \mathrm{g})$ in isoelectric focusing sample buffer were applied to the gel on LKB sample application strips placed near the electrodes and focused at 8 $\mathrm{W}$ for $5.5 \mathrm{hr}$ at $5^{\circ} \mathrm{C}$. The application strips were removed after $2 \mathrm{hr}$. Isoelectric point standards were soybean trypsin inhibitor $(\mathrm{p} I 4.55)$, $\beta$-lactoglobin A (pI 5.20), and bovine carbonic anhydrase B ( $/$ 5.85) (Pharmacia Inc., Piscataway, NJ).

Electrophoretic transfer of proteins to nitrocellulose. Isoelectric focusing gels were transferred in $0.7 \%$ acetic acid at $0.25 \mathrm{~A}$ for $5 \mathrm{hr}$ (Towbin et al., 1979). SDS gels were transferred in Laemmli's Tris-glycine electrophoresis buffer (Laemmli, 1970) containing 20\% methanol (Towbin et al., 1979) at $0.2 \mathrm{~A}$ for $20 \mathrm{hr}$ at $5^{\circ} \mathrm{C}$. After transfer, the gels were stained with Coomassie blue R-250 to confirm that all of the proteins were transferred. Vertical strips cut from the nitrocellulose sheets were also stained for protein with $0.1 \%$ amido black, $5 \%$ methanol, and $10 \%$ acetic acid for $5 \mathrm{~min}$, and then destained in 5\% methanol and $10 \%$ acetic acid. The remaining portion of the nitrocellulose sheets were blocked for $2 \mathrm{hr}$ in PBS containing 5\% nonfat milk, rinsed for $30 \mathrm{~min}$ in PBS containing $0.05 \%$ Tween-20, and then dried and stored in the dark.

Location of antibody proteins on nitrocellulose. Vertical strips from the protein transfers were rehydrated in PBS containing $0.1 \%$ Triton $\mathrm{X}-100$ and $1 \%$ nonfat milk for $1 \mathrm{hr}$. They were then incubated overnight in an appropriate dilution of antibody in PBS containing $1 \%$ nonfat milk. The strips were rinsed 4 times in PBS containing $0.05 \%$ Tween20 over a $30 \mathrm{~min}$ period. The strips were then incubated in an appropriate dilution of HRP-conjugated goat antimouse antibody (Sigma Chemical Co., St. Louis, MO) in PBS containing $1 \%$ nonfat milk for $2-$ $4 \mathrm{hr}$, then rinsed 4 times in PBS over a $30 \mathrm{~min}$ period and developed in $0.05 \%$ 4-chloronapthol and $0.01 \% \mathrm{H}_{2} \mathrm{O}_{2}$ in PBS. A purple-black reaction product was observed where the antibody was bound.

Immunocytochemical staining of $\mathrm{C}$. elegans. For immunocytochemical studies, $C$. elegans were washed from petri plates and fixed in $3.7 \%$ paraformaldehyde for $30 \mathrm{~min}$ at room temperature. Fixed animals (10 $\mu l$ ) were placed on a gelatin-subbed slide (Gall and Pardue, 1971), and a second subbed slide was pressed down on the first. The 2 slides were frozen on dry ice for more than 15 min, then quickly pried apart and immersed in acetone:methanol $(1: 1)$ which was also precooled on dry ice. After $3 \mathrm{~min}$ the animals were rehydrated through an ethanol: PBS series $(9: 1,7: 3,1: 1$, and $3: 7)$ at $0^{\circ} \mathrm{C}$. The animals were then left in $0.1 \%$ Triton $\mathrm{X}-100$ in PBS for $2-4 \mathrm{hr}$ at $0^{\circ} \mathrm{C}$, incubated in antibody for 6-8 $\mathrm{hr}$ at $4^{\circ} \mathrm{C}$, washed in PBS at $4^{\circ} \mathrm{C}$, and then incubated with rhodamineconjugated goat antimouse IgG (diluted 1:100 in PBS) for 2-4 hr at room temperature. The animals were washed in PBS, and the nuclei were stained with Hoechst 33258. Stained animals were mounted in $5 \% n$-propylgallate in glyccrol (Giloh and Sedat, 1982). Animals on control slides which received only secondary antibody were negative.

Microscopy. For fluorescence microscopy we used a Zeiss Standard 14 microscope equipped with epifluorescent illumination. Rhodamine fluorescence was selected with the Zeiss filter set 487715 . FITC fluorescence was selected with the Zeiss excitor BP 485/20, Zeiss beam splitter FT510, and Zeiss barrier filter LP590. Photographs were taken on Kodak Technical Pan film.

Other methods. Protein concentrations were determined by the method of Bradford (1976). BSA was used as a standard. 

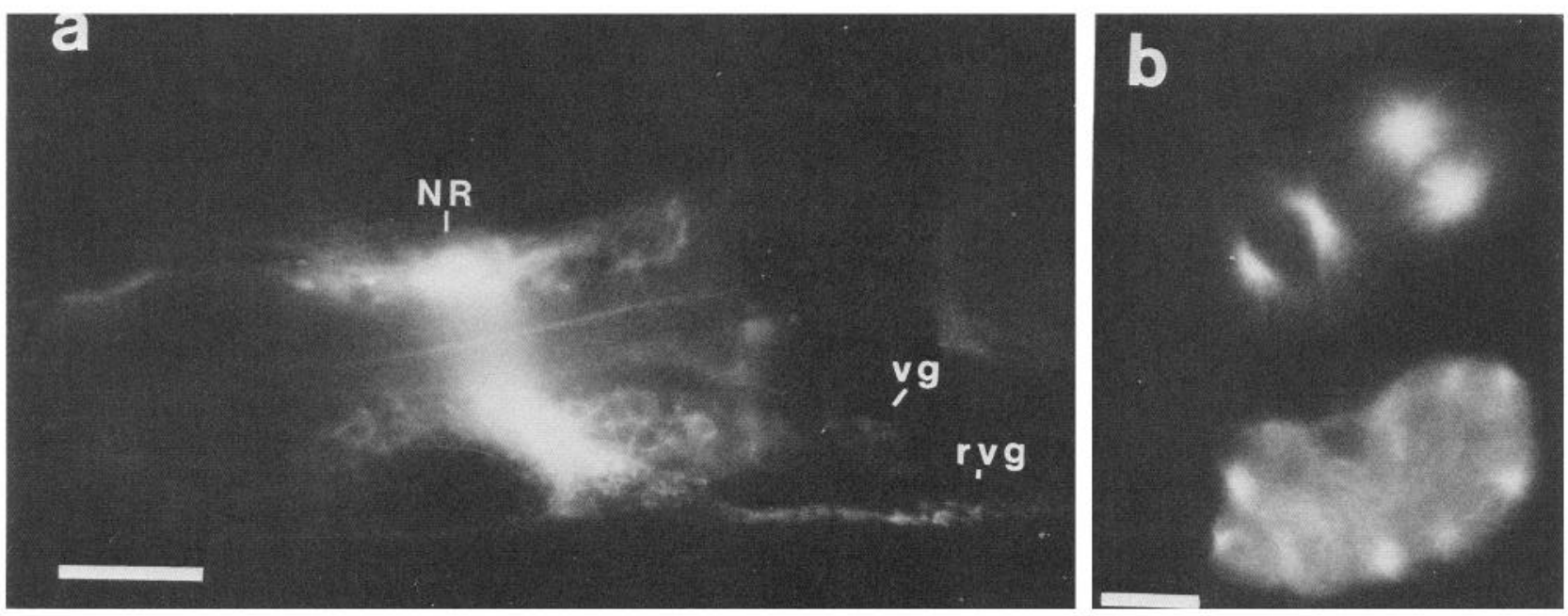

Figure 1. Immunocytochemical staining of neurons and mitotic spindle microtubules with antibody E6B6. Animals were fixed, permeabilized, and stained as described in Materials and Methods. $a$, Neuronal staining pattern in the head of a wild-type adult. $N R$ indicates the circumpharyngeal nerve ring, which comprises the processes of many sensory neurons, interneurons, and motor neurons. The nerve ring is the major neuropil of $C$. elegans. A number of nerve cell bodies are visible anterior and posterior to the nerve ring, including neurons of the ventral ganglion $(v g)$ and the retrovesicular ganglion ( $r v g$ ) (White et al., 1986). b. Staining of mitotic spindles in a 2-cell embryo (upper) and a multicell embryo (lower). Scale bars, $20 \mu \mathrm{m}$.

\section{Results}

Anti-tubulin antibodies that bind to specific neurons in $\mathrm{C}$. elegans

Nine monoclonal antibodies raised against tubulins from other species were tested by cytological staining of developmentally mixed populations of $C$. elegans to determine whether they bound to specific tubulin-containing structures. Most of these antibodies appeared to stain all of the microtubules in the animal without any apparent specificity. One of these, E6B6, gave particularly bright staining of all microtubules, and therefore served as a useful control antibody. Two other antibodies, 6-11B-1 and $2-28-33$, stained microtubules contained in specific neurons and bound to specific and different tubulins on immunoblots of focused $C$. elegans tubulin. The remainder of this section describes the association of these antibodies with $C$. elegans tubulins in situ and in vitro.

\section{Distribution of tubulins in C. elegans}

Antibody E6B6, which was raised against $\beta$-tubulin from squid optic lobe (T. Arai, personal communication), appeared to bind to all of the microtubules in C. elegans. In particular, this antibody labeled the entire nervous system, including cell bodies and processes, mitotic and meiotic spindles, and hypodermal microtubules (Priess and Hirsh, 1986) in embryos and adults. Figure $1 a$ shows the nerve ring area of a wild-type animal stained with antibody E6B6. The nerve ring and nerve cell bodies both anterior and posterior to the ring are labeled. Figure $1 b$ shows Ab E6B6 labeling of the mitotic spindles of a 2-cell and a multicell embryo.

Antibody 6-11B-1, which recognizes acetylated $\alpha$-tubulins in other species (Piperno and Fuller, 1985; LeDizet and Piperno, 1987), weakly stained the processes, but not the cell bodies, of most (possibly all) neurons. However, the cell bodies and processes of 6 neurons were intensely stained by this antibody (Fig. 2). These are the mechanosensory neurons ALML, ALMR, AVM, PLML, PLMR, and PVM known to transduce touch stimuli (Chalfie and Sulston, 1981). AVM and PVM normally stained slightly less intensely than the other mechanosensory neurons in these preparations. A seventh cell that stained slightly less intensely than AVM and PVM was identified as PVR, a unique neuron in the tail not known to be mechanosensory.

The mechanosensory neurons are known to contain bundles of large-diameter microtubules that mediate touch sensitivity in C. elegans (Chalfie and Sulston, 1981; Chalfie and Thomson, 1982). ALML, ALMR, PLML, and PLMR have lateral cell bodies and long lateral processes closely apposed to the cuticle. ALML and ALMR are situated in the midbody (on left and right sides, respectively) and have anteriorly directed processes that run into the head (Fig. 2, $a, b$ ). Each process sends off a branch that enters the nerve ring subdorsally (Fig. 2a). PLML and PLMR are bipolar neurons located in the lumbar ganglia of the tail. They each send one process posteriorly into the tail spike and a second process anteriorly to about the position of the ALM cell bodies (Fig. 2c). Each anterior process sends a branch into the ventral cord at the level of the vulva (not shown). The AVM cell body is located laterally just anterior to the ALMR cell body on the right side, while PVM is located laterally and anterior to the PLML cell body on the left. Each sends a process ventrally (along the body wall) into the ventral cord (Fig. $2 b$ ). The AVM and PVM processes run forward along the cord for characteristic distances [see Chalfie and Sulston (1981) and Chalfie and Thomson (1982) for a detailed analysis of the structure and function of the mechanosensory neurons].

The cell body of PVR, the seventh stained neuron, is situated in the right lumbar ganglion of the tail. It has a posterior process that goes into the tail spike like PLML and PLMR and an anterior process that extends along the right lumbar commissure into the ventral cord (Hall, 1977; White et al., 1986). PVR is not known to contain large-diameter microtubules.

Antibody 6-11B-1, unlike Ab E6B6, did not appear to label mitotic or meiotic spindles or other non-neuronal microtubules in C. elegans.

Antibody 2-28-33, which was raised against sea urchin sperm 

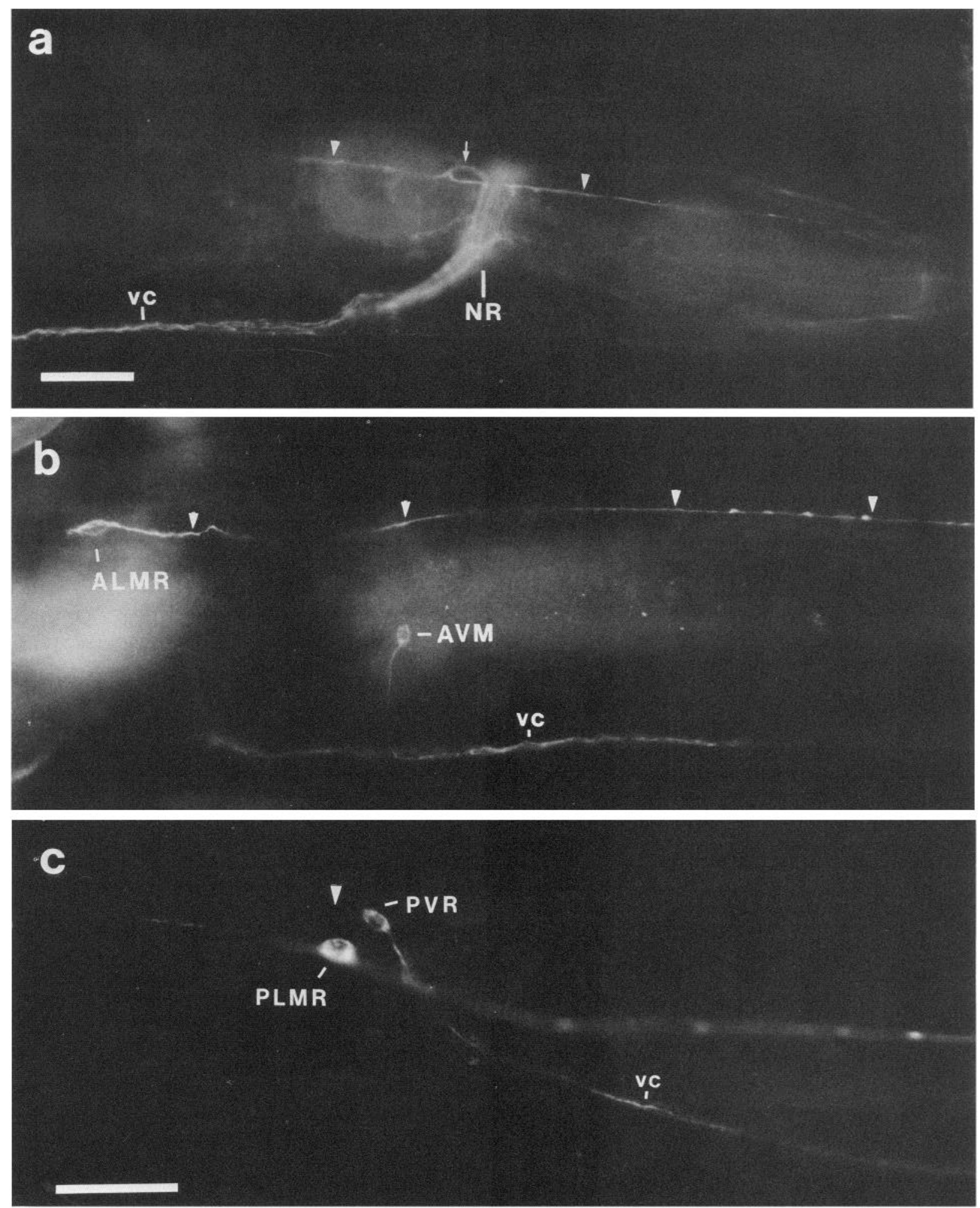

Figure 2. Immunocytochemical staining of neurons with antibody 6-11B-1. Animals were fixed, permeabilized, and stained as described in Materials and Methods. $a$, Lateral view of a stained wild-type head. The processes of many neurons are labeled as indicated by staining of the nerve ring $(N R)$ and ventral cord $(v c)$. The most intensely stained individual processes in the head belong to the bilaterally symmetric mechanosensory neurons ALML and ALMR, of which the process of ALMR (arrowheads) is seen here. A branch from this process into the nerve ring is indicated with an arrow. $b$, Lateral view of mechanosensory neurons ALMR and AVM. The ALM neurons each extend a process anteriorly (to the right) along a side of the animal into the head, while AVM extends a process ventrally into the ventral cord ( $v c)$, then forward along the cord into the head (see Chalfie and Thomson, 1982, for a complete description of the mechanosensory neurons). Scale as in panel $a$. $c$, The most intensely stained neurons in the tail are the bilaterally symmetric mechanosensory neurons PLML and PLMR, and unique neuron PVR, of which PLMR and PVR are seen in this lateral view. These neurons are bipolar with a posterior process (stained but out of focus, thus indicated with an arrowhead for PVR) extending into the tail spike. The PLM neurons each extend a process anteriorly into the head, while PVR extends a process ventrally along the right lumbar commissure, then forward along the ventral cord (see White et al., 1986, and Hall, 1977, for a more complete description of PVR) Scale bars, $30 \mu \mathrm{m}$ 

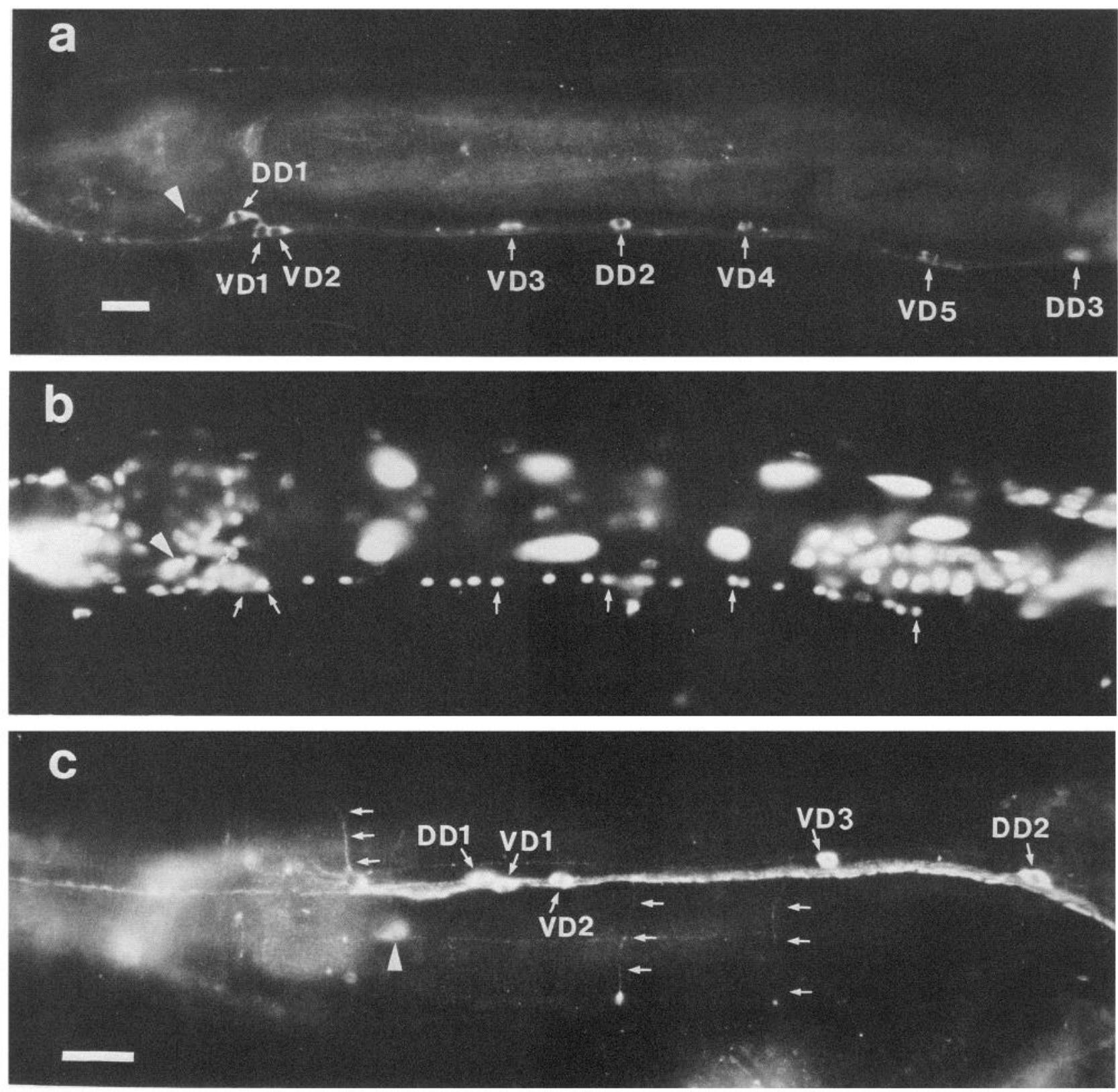

Figure 3. Immunocytochemical staining of ventral cord neurons with antibody 2-28-33. Wild-type animals were fixed, permeabilized, and stained as described in Materials and Methods. $a$, Lateral view of the anterior half of a stained wild-type animal showing the most intensely stained neurons of the ventral cord, which we have identified as the VD and DD motoneurons (see White et al., 1976, 1986, for a complete description of these neurons). Neurons DD1, VD1, and VD2 are actually located in the retrovesicular ganglion found at the anterior extreme of the ventral cord. An additional neuron cell body (arrowhead), anterior and dorsal to DD1, also stains (but less intensely) in the wild type. The identity of this neuron is unknown. $b$, The same animal stained in $a$ was also stained with Hoechst dye 33258 to reveal the positions of other ventral cord nerve cell bodies. Arrows point to the nuclei of cells stained by Ab 2-28-33. $c$, Ventral view of the anterior portion of an animal stained with antibody 2-2833. The VD and DD motoneurons send processes along the body wall extending from the the ventral cord to the dorsal cord as circumferential commissures (arrows). Although not shown here, the VD and DD commissures stained along the entire length of wild-type animals. The vertical striations in the anterior of this animal are probably hypodermal microtubules (Priess and Hirsh, 1986). Scale bars, $20 \mu \mathrm{m}$.

axonemes, also preferentially stained specific neurons in C. elegans. The processes of many (perhaps all) neurons were weakly stained by 2-28-33; however, most striking was the intense staining of 6 motoneurons in the ventral cord of $\mathrm{L} 1$ juveniles and 19 motoneurons in the ventral cord of later stage larvae and adults (Fig. 3). The number of stained motoneurons in different developmental stages is consistent with the identification of these as the DD and VD motoneurons; that is, there are 6 DD motoneurons in $\mathrm{L} 1$ juveniles and 13 VD motoneurons are added in the L2 stage (Sulston and Horvitz, 1977). To further verify these identifications, we mapped the positions of the stained cell bodies relative to other motor neuron cell bodies in the anterior half of the ventral cord for several wild-type animals. We compared these positions to the positions of VD and DD 

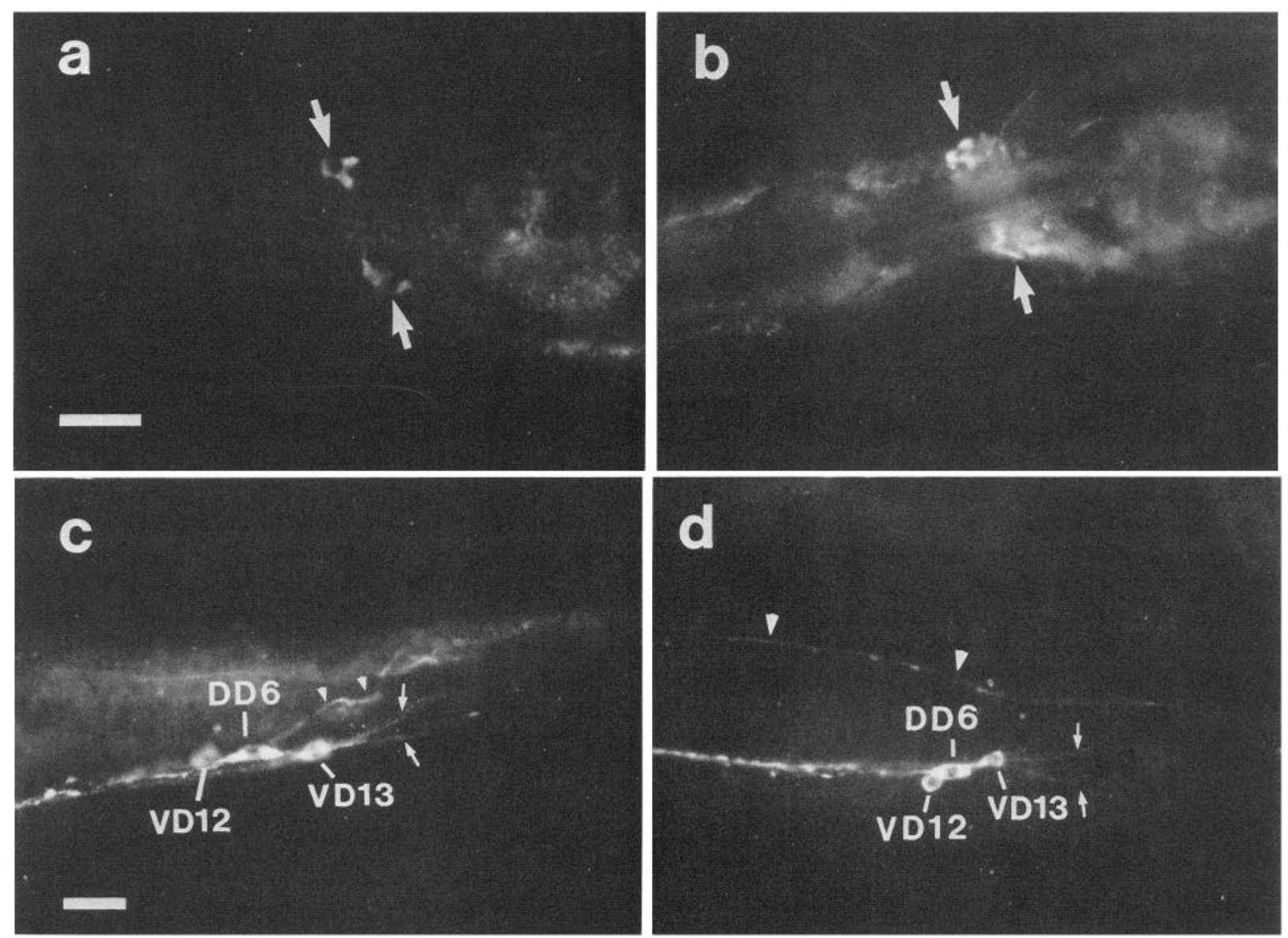

Figure 4. Immunocytochemical staining of neurons in the head and tail with antibody 2-28-33. Animals were fixed, permeabilized, and stained as described in Materials and Methods. Anterior is to the left. $a$, Lateral view showing 2 of the 4 neurons with large cell bodies that stain in the wild-type head. These are located at the dorsal and ventral midline closely apposed to the nerve ring. $b$, Ventral view showing the other 2 of the 4 neurons with large cell bodies that stain in the wild-type head. Both cell bodies are closely apposed to the nerve ring. $c$, Lateral view of the DD and VD motoneurons stained in the pre-anal ganglion found at the posterior extremity of the ventral cord. The lumbar commissures from both sides (arrows) can be seen as they enter the ventral cord. The additional process (arrowheads) that enters the ventral cord anterior to the lumbar commissure on the left side belongs to a neuron (probably to neuron DVB) in the dorsal rectal ganglion that stains moderately with Ab 2-28-33. $d$, Ventral view of the DD and VD motoneurons stained in the pre-anal ganglion. The lumbar commissures are visible (arrows), as is the anterior process of neuron PLML (arrowheads), which is only faintly stained by antibody 2-28-33. Scale bars, $20 \mu \mathrm{m}$.

motoneurons in the lineaged, serially reconstructed animals described by White et al. (1976). In all cases the positions were more consistent with the positions of VD and DD motor neurons than with any other motor neurons (e.g., compare Fig. 24 from White et al., 1976, with Fig. 3).

Finally, White et al. (1986) have shown that among the ventral cord motoneurons which extend axons to the dorsal side via commissures, the VD and DD neurons are the only ones that do not have commissures arising directly from their cell bodies. In addition, all of the VD and DD commissures leave the ventral cord on the right, with the exception of DD1 and VD2, which leave the cord on the left. Both properties apply to the motoneurons stained with $\mathrm{Ab}$ 2-28-33 as shown in Figure 3.

Antibody 2-28-33 also stained several other neurons slightly less intensely than the VD and DD motoneurons (Fig. 4). Among these were 4 neurons in the head with large cell bodies closely apposed to the nerve ring (Fig. $4, a, b$ ). These neurons have unusual symmetry. Two are located on the midline of the animal, one dorsally and one ventrally. The other 2 neurons are bilaterally symmetric. The processes of these cells stained less intensely than the cell bodies; however, we have observed that the midline neurons are bipolar with one process extending into the nerve ring and the other extending posteriorly into a motor nerve cord. The only neurons that fit this description are the RME motoneurons described by White et al. (1986).

Antibody 2-28-33 also stained a single neuron in the ventral ganglion in the head and another neuron in the dorsorectal ganglion in the tail. The latter neuron extends a process into the ventral cord on the left side of the animal (Fig. 4c). Ab 2-2833 did not appear to stain mitotic or meiotic spindles or microtubules in other non-neuronal tissues in C. elegans, with the possible exception of the hypodermis (Fig. 3c).

It is clear from the cytological staining results that Abs 6-11B-1 and 2-28-33 preferentially bound to distinct subsets of neurons in the wild-type $C$. elegans nervous system. Most (perhaps all) of the neurons in each subset are functionally related (see Discussion). Since this observation might have important functional implications for the proteins recognized by these anti- 


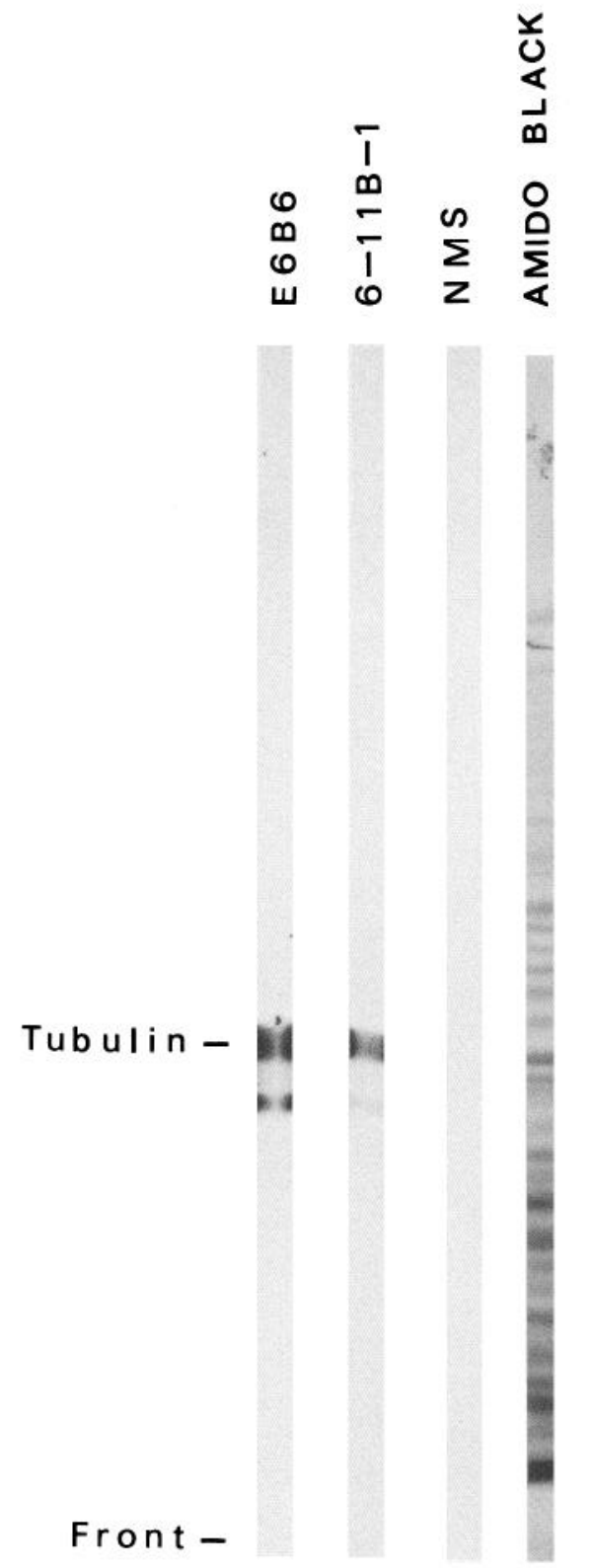

Figure 5. Reaction of monoclonal antibodies E6B6 and 6-11 B-1 with C. elegans proteins electrophoretically separated by SDS-gel electrophoresis and then transferred to nitrocellulose paper. Blots were stained with amido black to show the pattern of proteins present, and with antibodies 6-11B-1 and 2-28-33, and normal mouse serum (NMS) as described in Materials and Methods. Both antibodies bind specifically to proteins with the molecular weight of tubulin. They also both react slightly with bands below tubulin. These are probably proteolytic breakdown products of tubulin. C. elegans proteins were a high-speed supernatant of a developmentally mixed population of animals homogenized in a French press.

bodies, we felt it was essential to show that the antibodies specifically bind to different tubulins in C. elegans as they do in other species.

\section{Specificity of antibodies E6B6, 6-11B-1, and 2-28-33 for} tubulin

To determine whether these antibodies bind specifically to tubulin in C. elegans, we electrophoresed a high-speed supernatant

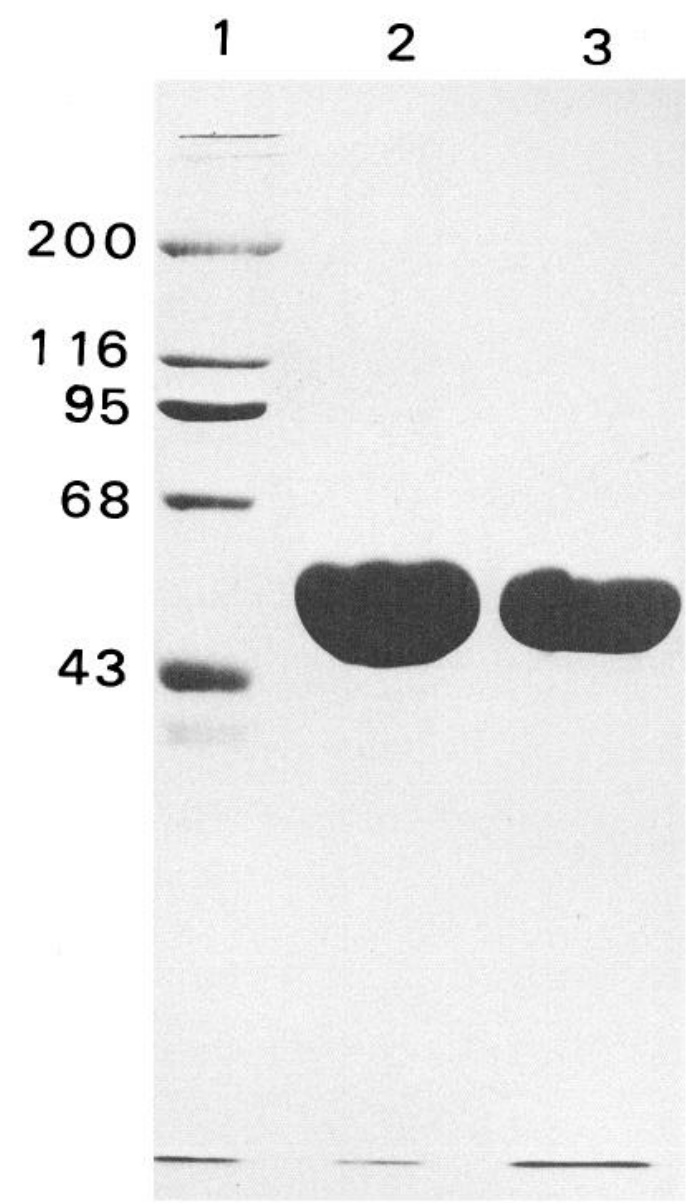

Figure 6. SDS-gel analysis of purified tubulin isolated from bovine brain and $C$. elegans. Tubulins were isolated as described in Materials and Methods and then electrophoresed on a minigel. The gel was stained with Coomassie blue R-250. Lane 1, molecular-weight standards. The numbers indicate the molecular weights $\times 10^{-3}$. Lane 2 , purified bovine brain tubulin, $18 \mu \mathrm{g}$. Lane 3, purified nematode tubulin, $18 \mu \mathrm{g}$.

of C. elegans homogenate on an SDS-polyacrylamide gel and transferred it to nitrocellulose paper. The nitrocellulose was cut into vertical strips, and the $C$. elegans proteins on the strips were reacted with the antibodies as described in Materials and Methods. Figure 5 shows the results of this experiment. Both Abs 6-11B-1 and E6B6 bound to proteins with the molecular weight of tubulin. Both antibodies also bound to the same minor bands below tubulin. These were probably proteolytic fragments of tubulin since they bound both Abs E6B6 and 6-11 B-1, which are different monoclonal antibodies against different tubulin epitopes (see below). Ab 2-28-33 did not bind to any proteins on the SDS-gel transfers.

Tubulin was isolated from C. elegans by the taxol procedure described in Materials and Methods. This tubulin and bovine brain tubulin were then electrophoresed on an SDS-polyacrylamide minigel shown in Figure 6. The $C$. elegans protein was undoubtedly tubulin since it coeletrophoresed with bovine brain tubulin on both SDS and isoelectric focusing gels, and it formed microtubules as determined by electron microscopy of negatively stained material (not shown).

Tubulin isolated by this procedure was pure. It contained no detectable contaminants on Coomassie blue-stained SDS gels that were heavily loaded with protein, as in Figure 6 , and it 


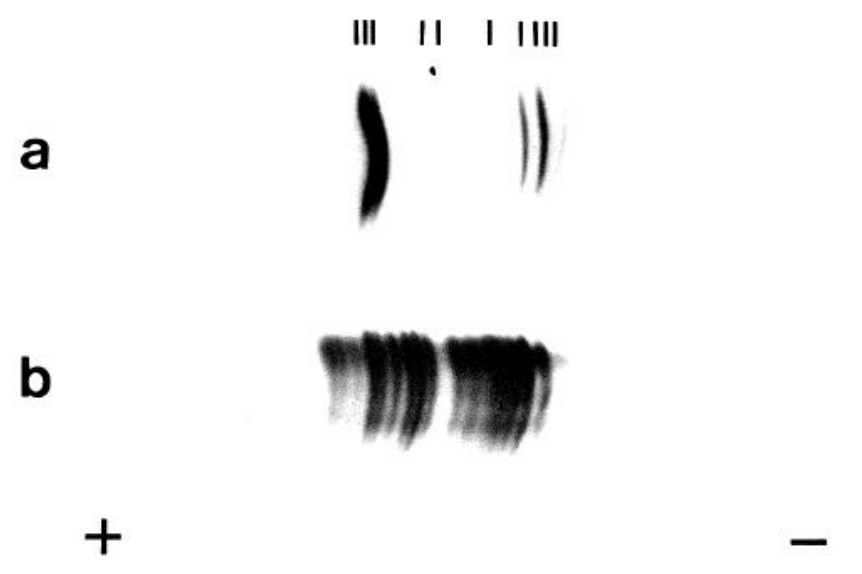

Figure 7. Tubulin isotypes from bovine brain and from C. elegans separated by isoelectric focusing. Gels were run as described in Materials and Methods. Each lane was loaded with $20 \mu \mathrm{g}$ purified tubulin. $a, C$. elegans tubulin contained at least 10 isotypes (only some of which are visible here) with most of the protein contained in $2 \alpha$ - and $2 \beta$-tubulins. $b$, Bovine brain tubulin. This preparation contained at least 16 visible isotypes as first described by Field et al. (1984). Both the bovine and C. elegans tubulins focus in the $\mathrm{pH}$ range of 5.3-5.8. Gels were stained with Coomassie blue R-250.

appeared to be cleaner than phosphocellulose-purified bovine brain tubulin, which is at least $96 \%$ pure (Detrich and Williams, 1978).

Since $\mathrm{Ab} 2-28-33$ bound to tubulin separated on isoelectric focusing gels (see below), but not to tubulin separated by SDSPAGE, we suspected that the antigenicity of tubulin for Ab 2-2833 was lost during the SDS-gel electrophoresis. To test this we spotted onto nitrocellulose strips native $C$. elegans tubulin and tubulin that was heated at $100^{\circ} \mathrm{C}$ in $5 \% \beta$-mercaptoethanol and $2 \%$ SDS. The strips were then blocked and reacted with the antibodies in the same way that we prepared immunoblots. We found that native tubulin bound Abs 2-28-33, 6-11B-1, and E6B6 well, but that after it was heated in SDS and $\beta$-mercaptoethanol, the tubulin bound only Abs 6-11B-1 and E6B6, but not 2-28-33 (data not shown). These results indicate that $A b s$ E6B6 and 6-11B-1 are specific for tubulin, whereas Ab 2-28-33 may be specific for tubulin that has not been denatured with SDS and $\beta$-mercaptoethanol.

\section{Isoelectric focusing of C. elegans tubulin}

We next attempted to determine whether these antibodies could distinguish between different tubulin isotypes separated by isoelectric focusing. Isoelectric focusing gels of the purified $C$. elegans tubulin and bovine brain tubulin are shown in Figure 7. The $C$. elegans tubulin appears to contain fewer isotypes than the bovine brain tubulin. The $\alpha$-tubulins have a more acidic isoelectric point than the $\beta$-tubulins in $C$. elegans (as in most other species) as determined by 2-dimensional gel electrophoresis (data not shown). There appear to be 2 major $\alpha$-tubulin variants and 2 major $\beta$-tubulin variants in $C$. elegans. There are also at least 3 minor tubulin isotypes visible in Figure 7, and we could count an additional 3 that stained very faintly for a total of at least 10 isotypes. In contrast, the bovine brain tubulin resolves into at least 16 visible isotypes in this gel system.

To estimate the isoelectric points of the $C$. elegans tubulin isotypes we ran an isoelectric focusing gel containing lanes of C. elegans tubulin alternating with isoelectric focusing standards. The $\mathrm{p} I \mathrm{~s}$ of the $10 \mathrm{C}$. elegans tubulins were estimated to

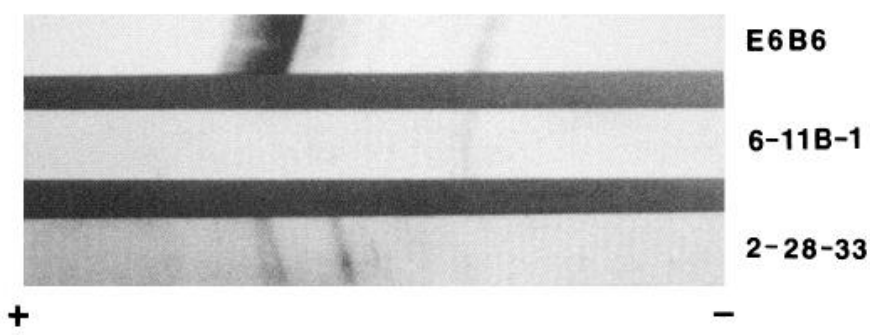

Figure 8. Reaction of monoclonal antibodies E6B6, 6-11B-1 and 2-2833 with $C$. elegans tubulin isotypes separated by isoelectric focusing (different gel than Fig. 7) and then electrophoretically transferred to nitrocellulose paper as described in Materials and Methods. $a$, Ab 2-2833 bound weakly to the 2 principal $\beta$-tubulins, and it bound strongly to one of the minor $\beta$-tubulins. $b$, Ab 6-11B-1 bound a single $\alpha$-tubulin isotype that we believe is the more basic of the 2 principal $\alpha$-tubulins. $c$, Ab E6B6 appeared to bind strongly to all of the $\beta$-tubulins. It also showed a small amount of reactivity with $\alpha$-tubulins.

lie between 5.38 and 5.74. The 2 major $\beta$-tubulins had $\mathrm{p} I \mathrm{~s}$ near 5.40 and the 2 major $\alpha$-tubulins had p/s near 5.70 .

Figure 8 shows the immunoblot patterns of Abs E6B6, 6-11B1 , and 2-28-33 binding to $C$. elegans tubulins that were isoelectric focused as in Figure 7 and then transferred to nitrocellulose paper as described in Materials and Methods. Antibody E6B6, which was raised against $\beta$-tubulin from squid optic lobe (T. Arai, personal communication), bound the $C$. elegans $\beta$-tubulins strongly, and it had a small amount of reactivity for the $\alpha$-tubulins. Ab 6-11B-1, which was raised against acetylated $\alpha$-tubulin from sea urchin axonemes and is known to be specific for the acetylated form of $\alpha$-tubulin in several species (Piperno and Fuller, 1985; LeDizet and Piperno, 1986), bound to the major $C$. elegans $\alpha$-tubulin with the more basic $\mathrm{p} I$ (5.71) and did not appear to bind to the other major $\alpha$-tubulin nor to any of the $\beta$-tubulins. Ab 2-28-33, which was raised against sarkosylresistant ribbons isolated from sea urchin sperm axonemes (G. Piperno, personal communication), bound to $3 \mathrm{C}$. elegans $\beta$-tubulins, including the 2 major $\beta$-tubulins and a minor tubulin variant with $\mathrm{p} I 5.49$. Ab 2-28-33 must have a high affinity for this minor isotype since much more antibody bound to it than to the major tubulins.

\section{Discussion}

We have tested a large number of monoclonal antibodies raised to tubulins from different species for their ability to bind to subsets of microtubules in C. elegans. Three of these antibodies were chosen for further study because they stained microtubules generally (E6B6) or because they could distinguish subsets of identified neurons (6-11B-1 and 2-28-33). Antibody $6-11 \mathrm{~B}-1$, which was raised against acetylated $\alpha$-tubulin (Piperno and Fuller, 1985), stained all neurons to some extent, but preferentially stained the mechanosensory neurons and neuron PVR. The mechanosensory neurons are known to contain large bundles of 15-protofilament microtubules (Chalfie and Thomson, 1982). The cytological staining results suggest that these neurons also contain a large amount of acetylated $\alpha$-tubulin. Athough this antibody appeared to bind only 1 of the 2 major $\alpha$-tubulin variants on Western blots of isoelectric focused $C$. elegans tubulins, we cannot be certain if this is the isotype that is responsible for the intense staining of these neurons. For example, it is possible that many $\alpha$-tubulin isotypes are acetylated in C. elegans, as is known to be the case for other organisms (LeDizet and Piperno, 1987), but at the concentrations used, this antibody 
may not have been sensitive enough to detect the less abundant acetylated isotypes on immunoblots. Apparently, however, the 2 major $\alpha$-tubulin isotypes are not acetylated to the same extent. It would be interesting to know if these 2 tubulins are expressed in the same cells in C. elegans.

In other organisms, acetylated $\alpha$-tubulin is found in older, presumably more stable microtubules, which are also more resistant to colchicine- or nocodazole-induced depolymerization (LeDizet and Piperno, 1986). It is interesting in this regard that the 15-protofilament microtubules found in the mechanosensory neurons are nocodazole resistant and colchicine sensitive, whereas the 11-protofilament microtubules present in all neurons are sensitive to both (Chalfic and Thomson, 1982).

Antibody 2-28-33 recognizes sarkosyl-resistant ribbons from sea urchin sperm axonemes. The epitope for this antibody is unknown; however, it bound to $3 \beta$-tubulin variants on Western blots of isoelectric-focused $C$. elegans tubulins. These included the 2 major $\beta$-tubulin variants and one of the minor variants. The fact that $\mathrm{Ab}$ 2-28-33 strongly labeled a minor variant on Western blots suggests that its relative affinity for that variant was actually much stronger than its affinity for the major variants. The preferential staining of certain neurons seen with this antibody may therefore be the direct result of binding to the minor variant which we predict should be present at a relatively high concentration in the stained cells.

Interestingly, there is a striking similarity between the staining pattern seen with $\mathrm{Ab}$ 2-28-33 and an anti-GABA antibody (S. McIntire and R. Horvitz, personal communication). We attempted to double-label animals with $\Lambda$ b 2-28-33 and an antiGABA antibody, but the glutaraldehyde fixation necessary for staining with the anti-GABA antibody was incompatible with the 2-28-33 antibody stain (unpublished observations). Nevertheless, the anti-GABA antibody reportedly stains the VD and DD motoneurons, plus 4 neurons in the head (identified as the RME motoneurons described by White et al., 1986) and 1 in the dorsorectal ganglion. Judging from their description, these are probably the same cells that are stained intensely by $\mathrm{Ab}$ 2-28-33. A few additional cells are reportedly stained by antiGABA antibodies which we have not yet observed to be intensely stained with $\mathrm{Ab}$ 2-28-33 (S. McIntire and R. Horvitz, personal communication).

The VI and DI motoneurons of Ascaris lumbricoides have locations and morphologies essentially identical to the VD and DD motoneurons of $C$. elegans. The VI and DI motoneurons have been shown to contain GABA (Johnson and Stretton, 1986) and to have inhibitory synapses onto body muscles (Walrond et al., 1985). VD and DD are therefore likely to be inhibitory motoneurons in C. elegans as well.

As a byproduct of the molecular characterization of these antibodies, we found that tubulin isolated from Caenorhabditis elegans contains a minimum of 10 isotypes that can be separated by isoelectric focusing in the presence of ampholines. These include 2 major $\alpha$ - and 2 major $\beta$-tubulin variants plus 6 minor variants (probably $3 \beta$ - and $3 \alpha$-tubulins). This number of isotypes is consistent with recent studies showing that the $C$. elegans genome contains a minimum of $4 \beta$-tubulin and $5 \alpha$-tubulin genes (or pseudogenes) identified by homology to $C$. elegans and chicken tubulin gene probes (Gremke, 1987). Of these, 2 $\alpha$-tubulin and $3 \beta$-tubulin genes have been cloned and $2 \beta$-tubulin genes have been sequenced (Gremke, 1987; Savage et al., 1989; L. Gremke, M. Hamelin, and J. Culotti, unpublished results).
Presently there are 2 major hypotheses to explain the presence of multiple tubulin genes in multicellular organisms. The multitubulin hypothesis suggests that different tubulin isotypes are required for the different functions of microtubules. The existence of interspecies conserved isotype classes and the finding that some tubulin isotype classes exhibit markedly preferential expression in certain tissue/cell types in different species lend support to this idea (see Cleveland and Sullivan, 1985, for review). The second hypothesis proposes that different tubulin genes exist to allow differential regulation of functionally equivalent tubulins in different subcellular locations, at different times in the cell cycle, at different times in development, or in different develomental pathways. This hypothesis gains principal support, first, from the genetic experiments of Raff and coworkers (Kemphues et al., 1982), who demonstrated that in Drosophila all microtubules in developing spermatids are composed principally of a single multifunctional $\beta$-tubulin isotype, and, second, from the findings of Lopata and Cleveland (1987) and Lewis et al. (1987) that most, if not all, cellular microtubules are assembled as copolymers of available isotypes. These hypotheses are not mutually exclusive.

The preferential cytochemical staining observed with Abs 2-2833 and 6-11B-1 suggests that specific tubulin isotypes are greatly enriched in certain subpopulations of identified neurons in $C$. elegans. Preferential staining is not just a function of antibody concentration since varying concentrations of Ab E6B6, which appears to stain all microtubules, does not mimic the staining patterns seen with Abs 2-28-33 or 6-11B-1 (unpublished observations), which are also clearly different from each other. An alternative explanation to our results is that the epitopes recognized by these antibodies are present at high concentrations in many cells, but are somehow masked in all cells except the ones that stain intensely. We cannot rule out this possibility. However, since the antibodies each recognize a subset of isotypes, the simplest model is that different neurons express specific tubulins in different amounts, cither as primary gene products or as posttranslational modifications of these gene products. Of course, we do not know if this enrichment is of any functional significance or if it only represents an example of differential expression. However, most (possibly all) of the neurons preferentially stained by $\mathrm{Ab}$ 2-28-33 are related in the sense that they contain GABA and all but one of the neurons preferentially stained by $6-11 \mathrm{~B}-1$ are known to have bundles of 15-protofilament microtubules and to be functionally related. Whether the tubulin isotypes recognized by $\mathrm{Abs}$ 2-28-33 and 6-11B-1 have specific functions in these sets of related neurons which cannot be replaced by other tubulins could be further addressed by the identification and analysis of mutants affecting these isotypes or by modifying the genes that encode them in vitro and reintroducing these genes back into live animals (Fire, 1985).

Finally, anti-tubulin monoclonal antibodies that differentially stain ncurons in the vertebrate nervous system have also been identified by a number of workers (Cumming et al., 1983; Tremblay et al., 1985; Draber et al., 1988). In these cases, no hints concerning the possible functional significance of the stained tubulin isotypes were found; however, these may also represent examples of tubulin isotype segregation which mediate some important function in certain neurons.

\section{References}

Aamodt, E. J., and J. G. Culotti (1986) Microtubules and microtubuleassociated proteins from the nematode Caenorhabditis elegans: Pe- 
riodic cross-links connect microtubules in vitro. J. Cell Biol. 103: 23-31.

Aamodt, E. J., and R. C. Williams, Jr. (1984) Microtubule-associated proteins connect microtubules and neurofilaments in vitro. Biochemistry 23: 6023-6031.

Albert, P. S., S. Brown, and D. L. Riddle (1981) Sensory control of dauer larva formation in Caenorhabditis elegans. J. Comp. Neurol. 198: 435-451.

Bradford, M. M. (1976) A rapid and sensitive method for the quantitation of microgram quantities of protein utilizing the principle of protein dye binding. Anal. Biochem. 72: 248-254.

Brenner, S. (1974) The genetics of Caenorhabditis elegans. Genetics 77: $71-94$

Chalfie, M., and J. Sulston (1981) Developmental genetics of the mechanosensory neurons of Caenorhabditis elegans. Dev. Biol. 82: 358370.

Chalfie, M., and J. N. Thomson (1982) Structural and functional diversity in the neuronal microtubules of Caenorhabditis elegans. J. Cell Biol. 93: 15-23.

Cleveland, D. W., and K. F. Sullivan (1985) Molecular biology and genetics of tubulins. Annu. Rev. Biochem. 54: 331-365.

Cumming, R., R. D. Burgoyne, and N. A. Lytton (1983) Differential immunocytochemical localization of $\alpha$-tubulin and $\beta$-tubulin in cerebellum using monoclonal antibodies. Cell Biol. Int. Rep. 3: 10471053.

Detrich, H. W., III, and R. C. Williams, Jr. (1978) Reversible dissociation of the alpha-beta dimer of tubulin from bovine brain. Biochemistry $17:$ 3900-3907.

Draber, P., L. A. Lagunowich, E. Draberova, V. Vicklicky, and I. Damjanov (1988) Heterogeneity of tubulin epitopes in mouse fetal tissues. Histochemistry 89: 485-492.

Field, D. J., and J. C. Lee (1985) Isoelectric focussing and two dimensional electrophoresis of tubulin using immobilized $\mathrm{pH}$ gradients under denaturing conditions. Anal. Biochem. 144: 584-592.

Field, D. J., R. A. Collins, and J. C. Lee (1984) Heterogeneity of vertebrate brain tubulins. Proc Natl. Acad. Sci. USA 81: 4041-4045.

Fire, A. (1985) Integrative transformation of Caenorhabditis elegans. EMBO J. 5: 2673-2680.

Gall, J. G., and M. L. Pardue (1971) Nucleic acid hybridization in cytological preparations. Methods Enzymol. 21: 470-480.

Giloh, H., and J. W. Sedat (1982) Fluorescence microscopy: Reduced photobleaching of rhodamine and fluorescein protein conjugates by n-propyl gallate. Science 217: 1252-1255.

Gremke, L. (1987) Cloning and molecular characterization of the tubulin genes of Caenorhabditis elegans: Nucleotide sequence analysis of a $\beta$-tubulin gene. Ph.D. dissertation, Northwestern University, Evanston, IL.

Hall, D. H. (1977) The Posterior Nervous System of the Nematode Caenorhabditis elegans, Ph.D. Dissertation, California Institute of Technology.

Johnson, C. D., and A. OW. Stretton (1986) GABA-immunoreactivity in inhibitory motor neurons of the nematode Ascaris. J. Neurosci. 7: 223-235.

Kemphues, K. J., T. C. Kauffman, R. A. Raff, and E. C. Raff (1982) The testes-specific beta-tubulin subunit in Drosophila melanogaster has multiple functions in spermatogenesis. Cell $31: 655-670$.

Laemmli, U. K. (1970) Cleavage of structural proteins during the assembly of the head of bacteriophage T4. Nature 227: 680-685.
LeDizet, M., and G. Piperno (1986) Cytoplasmic microtubules containing acetylated $\alpha$-tubulin in Chlamydomonas reinhardtii: Spatial arrangement and properties. J. Cell Biol. 103: 13-22.

LeDizet, M., and G. Piperno (1987) Identification of an acetylation site of Chlamydomonas $\alpha$-tubulin. Proc. Natl. Acad. Sci. USA 84 . 5270-5274.

Lewis, J. A., and J. A. Hodgkin (1977) Specific neuranatomical changes in chemosensory mutants of the nematode Caenorhabditis elegans. J. Comp Neurol. 172: 489-510.

Lewis, S. A., W. Gu, and N. J. Cowan (1987) Free intermingling of mammalian $\beta$-tubulin isotypes among functionally distinct microtubules. Cell 49: 539-548.

Lopata, M. A., and D. W. Cleveland (1987) In vivo microtubules are copolymers of available $\beta$-tubulin isotypes: Localization of each of six vertebrate $\beta$-tubulin isotypes using polyclonal antibodies elicited by synthetic peptide antigens. J. Cell Biol. 105: 1707-1720.

Perkins, L. A., E. M. Hedgecock, J. N. Thomson, and J. G. Culotti (1986) Mutant sensory cilia in the nematode Caenorhabditis elegans. Dev. Biol. 117: 456-487.

Piperno, G., and M. T. Fuller (1985) Monoclonal antibodies specific for an acetylated form of $\alpha$-tubulin recognize the antigen in cilia and flagella from a variety of organisms. J. Cell Biol. 101: 2085-2094.

Priess, J. R., and D. I. Hirsh (1986) Caenorhabditis elegans morphogenesis: The role of the cytoskeleton in elongation of the embryo. Dev. Biol. 117: 156-173.

Savage, C., M. Hamelin, J. G. Culotti, A. Coulson, D. G. Albertson, and M. Chalfie (1989) $m e c-7$ is a $\beta$-tubulin gene required for production of 15-protofilament microtubules in Caenorhabditis elegans. Genes and Development 3: 870-881.

Shelanski, M. L., F. Gaskin, and C. R. Cantor (1973) Microtubule assembly in the absence of added nucleotides. Proc. Natl. Acad. Sci. USA $70: 765-768$.

Sulston, J. E., and H. R. Horvitz (1977) Postembryonic cell lineages of the nematode Caenorhabditis elegans. Dev. Biol. 56: 110-156.

Sulston, J. E., E. Schierenberg, J. G. White, and J. N. Thomson (1983) The embryonic cell lineage of the nematode Caenorhabditis elegans. Dev. Biol. 100: 64-119.

Towbin, H., T. Staehelin, and J. Gordon (1979) Electrophoretic transfer of proteins from polyacrylamide gels to nitrocellulose sheets: Procedure and some applications. Proc. Natl. Acad. Sci. USA 76: 43504354.

Tremblay, J. P., C. Gravel, and R. Hawkes (1985) A monoclonal antibody to $\beta$-tubulin distinguishes a subset of neurons and axons in the chick ciliary ganglion. Can. J. Biochem. Cell Biol. 63: 458-469.

Walrond, J. P., I. S. Kass, A. O. W. Stretton, and J. E. Donmoyer (1985) Identification of excitatory and inhibitory motoncurons in the nematode Ascaris by electrophysiological techniques. J. Neurosci. 5: $1-8$.

Weingarten, M. D., A. H. Lockwood, S.-Y. Hwo, and M. W. Kirschner (1975) A protein factor essential for microtubule assembly. Proc. Natl. Acad. Sci. USA 72: 1858-1862.

White, J. G., E. Southgate, J. N. Thomson, and S. Brenner (1976) The structure of the ventral nerve cord of Caenorhabditis elegans. Phil. Trans. R. Soc. London [Biol.] 275: 327-348.

White, J. G., E. Southgate, J. N. Thomson, and S. Brenner (1986) The nervous system of Caenorhabditis elegans. Phil. Trans. R. Soc. London [Biol.] 314: 1-340. 